\title{
Personal Identity, the Temporality of Agency and Moral Responsibility
}

\author{
WIN-CHIAT LEE \\ Wake Forest University
}

\section{Introduction}

The question of personal identity over time is essential to the ascription of responsibility in our moral practice. This is because in ascribing moral responsibility, we want to know to whom a certain act should be attributed after it has been committed. After someone has been shot to death, we are interested in finding out who among the presently existing persons is the one who pulled the trigger.

It is personal identity, rather than some other kind of identity, which is important in the ascription of moral responsibility. This is because even though the law often may use such notions as collective or vicarious responsibility to establish a person's liability for another's negligence or crime, we nevertheless have the conviction that moral responsibility is personal, i.e., that a person may be held morally responsible for a certain act only if he himself has done it. Perhaps this is because we think that only individual persons are agents capable of acts and hence all acts must be acts of individuals. Locke might have had this in mind when he wrote, "In this personal identity is founded the right and justice of reward and punishment."1

It is quite clear that moral responsibility, as we understand it, presupposes personal identity over time. But it is not obvious that our idea of moral responsibility presupposes a particular metaphysical account of the nature of personal identity over time such that if that account turned out to be wrong, our idea of personal moral responsibility would be thereby rendered less plausible. My topic in this paper is just this question of the relevance of the metaphysics of personal identity to the idea of moral responsibility.

\section{Parfit's View}

Derek Parfit thinks that the metaphysics of personal identity is relevant to the question of moral responsibility. He distinguishes between two kinds of theory of personal identity, namely, the Reductionist View (or the Complex View) and the Non-Reductionist View (or the Simple View). ${ }^{2}$

'John Locke, An Essay concerning Human Understanding, II XXVII 18.

${ }^{2}$ Derek Parfit made the distinction between the Simple View and Complex View in "Later Selves and Moral Principles," an essay collected in A. 
For Parfit, whether the Reductionist or the Non-Reductionist View turns out to be true should affect our view regarding moral responsibility.

The Reductionist View is mainly an ontological thesis about personhood and personal identity. As a thesis about personal identity, it takes the fact of the continued existence of a person through time to be complex and analyzable into other kinds of fact. ${ }^{3}$ Hence, on the Reductionist View, personal identity is not ontologically basic; it is only a logical construct out of other basic (or more basic) facts. Reductionists have this view about personal identity because they are also reductionists about personhood. According to Parfit, all reductionists believe that "[a] person's existence just consists in the existence of a brain and body, and the occurrences of a series of interrelated physical and mental events."4 Since there is nothing more to a person than this, the identity of a person over time cannot be a further fact than the spacio-temporal continuity of his brain or body, or some interrelations between some physical events or mental events at different times.

According to one version of the Reductionist View, personal identity consists in psychological continuity, i.e., certain interrelations between non-identical mental events at different times. ${ }^{5}$ The fact that it is one and the same person having different experiences at different times is simply the fact that there are certain interrelations between these non-identical mental events. For Parfit, psychological continuity is the holding of overlapping chains of strong psychological connectedness and psychological connectedness is the holding of direct psychological

Montefiore ed., Philosophy and Personal Relations (London: Routledge and Kegan Paul, 1973), pp. 137-169. That distinction is basically the same as the distinction between the Reductionist View and the NonReductionist View Parfit draws later in his book, Reasons and Persons (Oxford: Oxford University Press, 1984) (hereafter abbreviated as RP). The two different sets of terminologies bring out different important aspects of the distinction.

${ }^{3}$ In the traditional sense of analysis, the analysis of a proposition is supposed to be not only logically equivalent, but also in some sense more basic than the proposition. See Eli Hirsch, "Hume's Distinction Between Genuine and Fictitious Identity," Midwest Studies in Philosophy, Vol. VIII, 1983, p. 326.

${ }^{4} R P$, p. 211. Parfit refers to mental events instead of mental states because the latter might presuppose the existence of subjects.

5The relation into which personal identity is analyzable is what John Perry calls "the unity relation." See Perry, "The Problem of Personal Identity," in Perry ed., Personal Identity (Berkeley and Los Angles: University of California Press, 1975), p. 9. There are different versions of the Reductionist View because there are different views on what this unity relation is supposed to be. 
connections, l.e., direct causal relations between mental states, such as that between an experience and the memory of $1 t$, or between an intention and an act. ${ }^{6}$

There are other versions of the Reductionist View. One might take a person's identity over time to be analyzable Into the spacio-temporal continuity of the body or the brain. Or one could take it to be analyzable into a combination of psychological continuity and bodily continuity. In this paper, I shall limit my discussion of the Reductionist View to the version which takes personal identity to be analyzable into psychological continuity. My comments on this version need not be applicable to other versions of the Reductionist View because they might involve completely different sets of questions.

The Non-Reductionist View, on the other hand, takes the fact of personal identity over time to be simple in the sense that it is unanalyzable. Thomas Reid, for example, wrote, "If you ask a definition of Identity, I confess I can give none; it is too simple a notion to admit of logical definition."7 On the Non-Reductionist View, the fact that it is one and the same person at different times cannot be analyzed into facts about the interrelations between some mental events, or facts about the spacio-temporal continuity of a body, or a brain, or any other facts which can be described without employing the concept of personal identity over time. According to Parfit, Non-Reductionists believe that a person is a separately existing entity, i.e., an entity which is other than his brain and body, and the mental and physical events attributable to him-an entity often referred to as "the pure ego." Because of this belief about personhood, Non-Reductionists also believe that personal identity over time cannot be analyzed into facts about these other entities and is hence a further fact than these other facts. ${ }^{8}$ On the Non-Reductionist View, personal identity over time is ontologically basic; it consists simply in the continued existence of the separately existing entity, 1.e., the "pure ego." We need and can say no more about what it is.

'See RP, p. 206. Parfit does not specify what "strong connectedness" means, except that there should be "enough" psychological connections. This characterization will suffice for our purposes.

7Thomas Reid, Essays on the Intellectual Powers of Man, A. D. Woozley ed. (London: MacMillan 1941), p. 202.

${ }^{8}$ On this account of the Non-Reductlonist View, it is not clear what Parfit can possibly mean by the claim that personal identity is a deeper fact on the Non-Reductionist View. It seems that either Parfit means by "a deeper fact" no more than "a further fact" or he might have to explain the "depth" of a metaphysical fact in terms of its moral importance and hence beg the very question of its relevance to morality. For similar criticisms, see Norman Daniels, "Moral Theory and the Plasticity of Persons," The Monist, 62, 1979, p. 269. 
One might want to claim that the only theory which can account for a person's responsibility for his earlier acts is the one which takes personal identity to be simple and unanalyzable. On this view, if the Reductionist View turns out to be true, we will not be able to justify our punishing someone for his earlier crime simply on the ground that he is responsible for his own act and hence deserves punishment for it. ${ }^{9}$ In that case, we might have to either seek a utilitarian justification for punishment or forgo punishment altogether. Parfit does not agree with this view completely. Parfit does agree, on the one hand, that if the Reductionist View should turn out to be true, what he calls "the Extreme Claim," i.e., the claim that no one deserves punishment for his earlier crime, might be rendered more plausible. ${ }^{10}$ But, on the other hand, Parfit also thinks that even then it might still be possible to deny the Extreme Claim, presumably by arguing that psychological continuity, by itself, is sufficient to ground desert for past crimes. 11 Parfit might be right on the latter point. But it is unclear to me why he should think in the first place that the Extreme Claim can be rendered more defensible by the Reductionist View. In this paper, I shall argue for a stronger position than Parfit's, namely, that our idea of a person's responsibility for his earlier acts is as defensible on the Reductionist View as on the Non-Reductionist View and that the Reductionist View does not make the Extreme Claim any more plausible.

9This position is held, for example, by Vinit Haksar, See Haksar, Equality, Liberty, and Perfectionism (New York: Oxford University Press, 1979), esp. pp. 115-121.

"Parfit often uses the plural "Extreme Claims". In this paper, however, I am dealing with only one of these Extreme Claims--the one Parfit discusses in RP, pp. 234-325. Also, the question Parfit addresses is about desert for punishment while the one I am addressing in this paper is about responsibility. I think my question is more basic than Parfit's. For we deserve punishment for the wrongs we have committed only because we are responsible for them.

${ }^{11}$ RP, pp. 324-325. 


\section{Reductionism and the Extreme Claim}

It is not obvious how the Extreme Claim can be rendered more defensible by Reductionism. Parfit suggests the following view. When we are Non-Reductionists and believe in moral responsibility, we also believe that only personal identity as a further fact can justify the ascription of personal moral responsibility over time. ${ }^{12}$ If so, then we will no longer find it justifiable to hold a person responsible for his past acts when, perhaps as a result of thinking through the problem cases of fission and fusion of persons, we become Reductionists and realize that there is no further fact of personal identity.

I doubt that this is indeed our view even if we are Non-Reductionists. On the Non-Reductionist View, it is logically possible that what we consider to be the life of "one person" actually involves more than one pure ego. ${ }^{13}$ That is, on the Non-Reductionist View, there is no reason why the psychological continuity within the life of "one person" is not actually carried by a series of succeeding pure egos, each persisting only a very short period of time. If the further fact of personal identity is really as relevant to our ascription of responsibility as Parfit thinks, then we should think that the lack of personal identity within the life of "one person" should give us at least one good reason to think that one is not responsible for some acts with which one is still psychologically connected. But if our lives remain about the same when they are each owned by a series of egos as they are when they are each owned by one ego, it is not clear why the fact that there lacks a "deeper" unity within one's lifetime should gives us any reason at all to change our practice of ascribing responsibility.

At any rate, even when we are Non-Reductionists, we never bother to settle the question whether there is only one ego or many throughout "one person's" whole lifetime before we ascribe moral responsibility for past acts. One possible explanation of this is that, contrary to Parfit's claim, the further fact of personal identity over time never figures in our justification of personal moral responsibility even when we are Non-Reductionists. That is, even when we are Non-Reductionists, the conception of personhood and personal identity used in moral judgments does not involve beliefs about the ontological status of persons, at least not the kind at issue between the Reductionists and the Non-Reductionists. Therefore, we need not find personal moral responsibility less plausible when we change from the Non-Reductionist to the Reductionist View.

An alternative explanation is that when we are Non-Reductionists, somehow we are just able to assume that there is only one ego per lifetime. With this assumption, perhaps the view described by Parfit might indeed be our view when we are Non-Reductionists. But this does not mean that

12RP, pp. 324.

${ }^{13}$ Locke entertained this possibility in Essay, II XXVII 10. 
this view is therefore a tenable one, unless it can be supported by a plausible argument. But Parfit has not given us any clue as to what such an argument might be.

I shall now suggest an argument which attempts to show why it matters morally that personal identity is a further fact. One can perhaps argue that there are certain doubts about one's responsibility for one's past acts which can be raised only on the Reductionists View, but not on the Non-Reductionist View. Such doubts make sense only on the Reductionist View because on that view, personal identity is analyzable into facts about non-identical entities at different times-entities such as momentary experiences or mental events-and certain continuity relations between them.14 So if the Reductionist View turns out to be true, then by holding a person responsible at a later time for an earlier act of his, strictly speaking, one is actually holding a momentary entity accountable for the act of an earlier, but numerically different, momentary entity, to which the later momentary entity only happens to be related in some ways. ${ }^{15}$

To be sure, it is difficult to understand how an act can be attributed to a momentary entity such as a mental event or how that momentary entity can be held responsible for an act. But this only means that we need to bring in some logical constructs out of these mental events to allow us to talk about these events having subjects 80 that there will be some subjects of these events to be held morally responsible. But on the Reductionist View, there is no reason why we should prefer to use the logical construct of persisting persons as opposed to, say, the logical construct of momentary selves or momentary person-stages as the subjects of these mental events. ${ }^{16}$ These are equally logical constructs out of the same set of basic facts, i.e., the existence of certain mental events and certain interrelations between them; they are merely different ways of talking about the same set of facts using different sets of definitions or rules of construction. On the Non-Reductionist View, there is no further fact of personal identity over time to give us a further reason to prefer to talk about persisting persons as opposed to momentary person-stages.

To put the point differently, on the Reductionist View, personal tdentity is in at least one important regard similar to object identity. For example, we are reductionists about cars. That is, we believe that a car is

${ }^{14}$ This is perhaps the reason why traditionally some philosophers have called personal identity "fictional" when it turns out to be analyzable.

15Perhaps this is what Parfit is referring to when he says the unity of a person's life lacks "depth" on the Reductionist View. But it is still not clear why it is "depth" which personal identity lacks on the Reductionist View.

${ }^{16}$ There is no obvious reason that the latter is not possible. If we can construct the persistent self out of a series of interrelated momentary experiences on the Reductionist View, we should also be able to construct momentary selves out of momentary experiences. 
reducible to all the parts which make up the car. Hence, it does not make sense to ask whether my car really remains the same car after it has had most of its parts replaced over the years. It does not matter whether one says I still have the same car, or whether one says I finally have a different car after all these years of repairs. Neither description is closer to the truth than the other because they are only different ways of speaking about the same basic facts, i.e., that most of the parts in the car I am driving now are different from the parts in the car I was driving years ago. There is no further fact of car identity which allows us to prefer one description to the other. The difference lies merely in the different definitions of "the same car." In a more or less similar way, on the Reductionist View of personal identity, there is no further fact of personal identity to allow us to prefer the description in terms of persisting persons to the description in terms of momentary person-stages.

But if we use the construct of momentary person-stages or selves and make them the subjects of these momentary mental events, it will become puzzling why a later momentary self can be held responsible for the act of an earlier momentary self to which the later one is merely related in some ways. Furthermore, if we hold a momentary entity responsible for the act of another momentary entity simply because of some psychological relations existing between them, it is not obvious why we should stop at those relations. Why don't we also hold a person responsible for another's act simply because certain other relations, such as sympathy or similar character traits, exist between them?

So if the Reductionist View turns out to be true, one might be confronted with the following episode. At $t_{1}$, Rasko murdered a helpless old woman who also happened to be a greedy money-lender. At a later time, $t_{2}$, he was finally apprehended for murder. But he resisted arrest. Being a true believer in the non-existence of "pure ego," Rasko argued, "Why are you arresting me? I am Rasko-at- $t_{2}$, the present temporal stage of Rasko. But I have not committed any crime. An earlier person-stage, Rasko-at- $t_{1}$, to whom I am psychologically related, committed a murder. Yes, I remember killing the old woman. Yes, I have many of the beliefs and desires Rasko-at $t_{1}$ had. If he had not killed that greedy old woman, I would have done it myself. But you don't just go around arresting people because they think they remember having committed a crime or because they have evil thoughts. The question is whether they have done it. But I can't be the murderer and in fact this can't even be a case of partnership in crime because I was not even in existence when the murder took place at $t_{1}$. I think what you have here is at best a genuine case of mistaken identity."17 Note that it will not help to remind Rasko-at- $t_{2}$ of the fact that he is also the same person as Rasko-at- $t_{1}$, for stating this fact, on the

17This is very similar to Haksar's argument in Equality, Liberty, and Perfectionism, p. 114. 
Reductionist View, is merely stating another construction out of the same set of basic facts, i.e., that there is psychological continuity between Raskoat- $t_{1}$ and Rasko-at- $t_{2}$, and Rasko-at- $t_{2}$ is questioning precisely why one should prefer this construction to his. ${ }^{18}$

This is perhaps a more complete way of putting what Reid had in mind when he wrote, "Consciousness, and every kind of thought, are transient, and momentary, and have no continued existence; and, therefore, if personal identity consisted in the consciousness, it would certainly follow, that no man is the same person any two moments of his life; and as the right and justice of reward and punishment are founded on personal identity, no man could be responsible for his actions." 19

One should keep in mind that the argument 1 have described has not shown conclusively that if the Reductionist View turns out to be true, Rasko was not responsible or did not deserve punishment for the murder at the time of the arrest. But this is precisely Parfit's point. As he suggests, one might still be able to argue that the psychological continuity between Rasko-at- $t_{1}$ and Rasko-at- $t_{2}$ is enough to justify holding the latter responsible for what the former did. Furthermore, one might be able to explain why only the kind of psychological relation which exists between Rasko-at- $t_{1}$ and Rasko-at- $t_{2}$, but not the kind which exists between Rasko and somebody else who sympathizes with him, can justify the transfer of responsibility from one to the other. But none of this will affect Parfit's argument. This is because in such case the justification of holding Raskoat $t_{1}$ responsible for the murder will still be different from that for holding Rasko-at-t $t_{2}$ responsible. Hence one can still doubt that Rasko is responsible for his murder at a later time without at the same time doubting that he is responsible for it at the time of the murder. And this is presumably what is impossible on the Non-Reductionist View.

On the Non-Reductionist View, personal identity is not analyzable and hence not analyzable into relations between different momentary entities which do not really persist through time. If the Non-Reductionist View is true, then the act of murder is as much the act of Rasko at the time of his arrest as when he committed the murder; it is not by virtue of another fact, i.e., the fact of psychological continuity between Rasko-at- $t_{1}$ and Rasko-at- $t_{2}$ that we attribute the murder to Rasko at the time of the arrest. So on the Non-Reductionist View the relation of Rasko to the murder at the time of the arrest is exactly the same as the relation of Rasko to the murder at the time of the murder, it follows that nobody else except Rasko himself at different times can be held responsible for the murder. So on the Non-Reductionist View, certain doubts about a person's responsibility for his past acts cannot be sensibly raised.

10This is perhaps what Parfit means when he says that the fact of personal identity is trivial on the Reductionist View (RP, p. 326).

${ }^{19}$ Reid, Essays, pp. 214-215. 


\section{Agency and Temporal Extension}

Though it is true that on the Reductionist View persisting persons and momentary person-stages are equally constructs out of more basic facts and hence we have no reason to prefer either one of the two strictly from the point of view of ontology, these two constructs might not be equally relevant to moral theory. This is what I take to be the main problem with the argument I have described in the preceeding section.

For example, it is presupposed in that argument that an act can be attributed to a momentary person-stage. This is how we can possibly question Rasko-at- $t_{2}$ 's responsibility for the act of Rasko-at- $t_{1}$. But an act can only be attributed to an agent and an agent cannot be a momentary person-stage. Agency is always temporally extended because, first of all, an action always involves some kind of change and change is possible only when there is passage of time. ${ }^{20}$ That is, it always takes time for an act, such as a murder, to be completed, no matter how simple it is. Hence, to individuate an act, one will need to use the idea of the identity of an act through time which necessarily involves the identity of an agent through time.

Secondly, an act is an act and an act under a particular description only because it can be traced (perhaps causally) to the intention of the same agent to whom the act is attributed. Description of the intention behind an act, however, often depends on facts about the agent at different times or over a period of time, which can be long in some cases. For example, when Smith's gun fired and killed someone at $t_{1}$, whether that should be characterized as an act of murder, or as an accident resulting from an act of cleaning his gun, or in some other way, depends on what he did before and after $t_{1}$ and many other facts about him at those other times. Even on the most simplistic view of intentions as conscious mental states, time presumably has passed before an act is brought about by an intention.

${ }^{20}$ Presumably, actions are possible only if the passage of time is real because changes are real only if the passage of time is real. For an interesting discussion on the relation between realism about time and the possibility of agency, see Delmas Lewis, "Persons, Morality, and Tenselessness," Philosophy and Phenomenological Research, Vol. XLVII, No. 2, Dec. 1986, pp. 305-309. This article has the potential of raising doubts about our ability to accommodate the idea of agency on the Reductionist View. But it concerns a completely different array of problems which, for obvious reasons, I cannot discuss here. See also Ronald C. Hoy, "Becoming and Persons," Philosophical Studies 34 (1978), pp. 269-280. 
Thirdly, an agent deliberates. But as Aristotle rightly pointed out, an agent always deliberates about the future, i.e., what he will do in the future. This is because, according to Aristotle, it only makes sense for an agent to deliberate about what is up to him, l.e., what he can change, and only the future can be changed. ${ }^{21}$ Furthermore, in deliberating about the future, an agent does not deliberate simply on the basis of what he predicts to be his future desires and values. This is presumably because an agent sees many of his future desires and values as also up to him now.

For these reasons, it is therefore clear that an agent who is capable of any act at all must not only be something which persists through time and can be reidentified in time, but also think of himself that way. Now it should be also clear that if we attribute the murder to Rasko-at- $t_{1}$ and hold him responsible for it, we may do so only because we take Rasko-at- $t_{1}$ to be a stage of the temporally extended agent who has committed the murder. On our version of the Reductionist View, this amounts to claiming that Rasko-at-t $t_{1}$ is held responsible for the murder only because of his psychological continuity with other stages of the agent to whom the murder can be properly attributed. Now if we take the person persisting through time to be the temporally extended agent, we will no longer be able to see any important difference between holding Rasko-at- $t_{1}$ and holding Rasko-at- $t_{2}$ responsible for the murder at $t_{1}$. Rasko-at- $t_{2}$ is held responsible for the murder also because the murder at $t_{1}$ is attributable to him through his psychological continuity with other stages of Smith. On the Reductionist View, whatever psychological continuity with other stages of Rasko Rasko-at-t $t_{1}$ has should also be present in Rasko-at- $t_{2}$ if they are truly stages of one and the same person.22 This will also explain why the kind of relation which exists between Rasko and someone else who happens to think like him will not justify the transfer of responsibility from one to the other.

This objection can be answered in two different ways. First, one can take Reductionism to have skeptical implications and suggest that we give up using the ideas of agents and acts aitogether if Reductionism turns out to be true. This is because on Reductionism facts about persons persisting through time turn out, on analysis, to be facts about entities which do not so persist, and as I have argued, agency can only be realized in time. However, we have reason to follow this skeptical suggestion only if we cannot find an argument to ground the use of the idea of agency on facts about psychological continuity alone. But more importantly, if the

${ }^{21}$ Aristotle, Nichomachean Ethics, $1139 \mathrm{~b}$.

22Psychological continuity, unlike psychological connectedness, is a transitive relation. This should be clear from the definitions explained earlier in the main text. Furthermore, according to Parfit, since personal identity is a transitive relation, what personal identity consists in, i.e., psychological continuity, must also be transitive. See RP, p. 206. 
Reductionist View implies that we have to give up the idea of agency, it will not render the Extreme Claim more defensible. For if we give up the idea of agency, we will have to give up the idea of acts, and hence also the Idea of making claims and defending them with arguments. For the identity of a claim or an argument depends on the identity of a speaker and a speaker is a kind of agent. (Note that it took Rasko quite a while to make his argument.) Furthermore, it will not be possible then to make sense of the Extreme Claim as a moral claim. The Extreme Claim is certainly meant to say that it is wrong to punish someone on the grounds of personal responsibility over time. But if we are not allowed to use the concept of acts, how can we possibly understand punishing someone as an act and then characterizing it as wrong? Hence if we follow this suggestion and give up the idea of agency, we will not be rendering the Extreme Claim more defensible as a moral claim; all we will be doing is to render morality itself impossible. ${ }^{23}$ But, again, it is not clear that Reductionism warrants such strong skeptical conclusion.

The second answer is as follows. Let us grant that an act can only be attributed to a temporally extended subject. But this by no means shows that Rasko's argument for resisting arrest is wrong. Rasko perhaps can reply that this only shows that the murder can only be attributed to an agent who lasts long enough to commit a murder with a relevant intention, but this agent need not be Rasko the person who lasts long enough to confront an arrest at a later time. What we need is Parfit's distinction between psychological continuity and psychological connectedness, as explained earlier. One can argue that we do not need the psychological continuity of a person throughout his whole lifetime, l.e., the maximum of overlapping chains of psychological connections, to make sense of agency. What is really necessary for agency, one can argue, is a minimum of psychological connectedness, i.e., that there be direct causal relations between some relevant mental states or between an act and a relevant mental state.

The point is that we can perhaps take only a very small segment of a person's life and still understand why that person is an agent within that segment. So perhaps we can attribute the murder to only a small temporal segment of Rasko who constitutes a minimally temporally extended agent lasting just long enough to commit the murder with a relevant intention. But this is far from saying that the murder can also be attributed to any minimal segment of Rasko contemporary with the arrest. After all, Rasko could have died immediately after he fired the shots, and in such case we do not necessarily have any problem characterizing his act as an act of murder and attributing it to him.

${ }^{23}$ For a similar point, see Samuel Scheffler, "Ethics, Personal Identity, and Ideals of the Person," Canadian Journal of Philosophy 12, No. 2, June 1982, pp. 238-240. 
In short, we can propose to use the concept of a person* who consists of just enough psychologically connected stages to complete an act (or finish an argument) with a relevant intention, instead of the Reductionists' concept of a person who consists of the maximum number of psychologically continuous stages and hence can possibly last long enough to be held responsible for an act after it has been completed. We can then propose to treat person"s as agents. It is possible to treat person"s, as well as persons, as agents because a person*, by definition, lasts long enough to complete an act with a relevant intention. Now Rasko's defense will make sense again. What Rasko said at $t_{2}$ essentially means: "Why am I, a person" who is trying to finish an argument now, held responsible for the murder committed by a different person"?" Granted, person"s and persons, on this account, are ontologically the same kind of entity for Reductionists; they are both constructs out of entities such as momentary experiences or mental events. Hence, we have no more reason to prefer to talk about person"s than to talk about persons. But, as before, this will only be an advantage for Rasko's argument because it will also imply that we have no more reason to talk about persons than to talk about person's.

But this idea of minimally extended agent seems arbitrary. If we construct persisting agents out of psychologically connected personstages, it must be at least partly because psychological connectedness is important for agency and we are interested in "unifying" person-stages which are psychologically connected. It will therefore be quite arbitrary to use a construction which uses psychological connectedness to "unify" some person-stages into an agent, but neglects others which are also psychologically connected with them. But if we "unify" all person-stages which are psychologically connected with the murder into one agent and attribute the murder to this agent, then we will be attributing the murder to an entity which does last long enough to be held responsible for it after it has been committed. This by no means renders the Extreme Claim more defensible because on this conception of agency, most people can still be held responsible for their past acts, as long as these acts are not so far back that there is no psychological connection with them. This might imply that one's responsibility for a certain act one committed in the past will weaken over time on the Reductionist View because one's psychological connection with this act will also weaken over time. But even this by no means amounts to the Extreme Claim.

A related point can be made by examining what it is like to be an agent who accepts the Extreme Claim. Since deliberation is always about the future, an agent, in deliberating about his acts, inevitably will have to identify with some future stages of himself with whom he is psychologically connected and see them as his agency in the future. That is, an agent inevitably takes "prospective" responsibility for some future stages of himself. If the same agent in the meantime accepts the Extreme Claim 
and refuses to take "retrospective" responsibility for any of his past acts, no matter how closely psychologically connected he is with these past acts, then there will be an asymmetry in his attitude towards the future and the past. This asymmetrical view towards time might be defensible. But it will be difficult to understand how it will be rendered more defensible on the Reductionist View than on the Non-Reductionist View. Even on the Reductionist View, this asymmetry in one's attitude towards future stages and past stages of oneself with whom one is equally psychologically connected seems entirely arbitrary, if at all psychologically possible.

\section{Conclusion}

Morality does not make sense without moral agents. To think of ourselves as moral agents, however, we will have to think of ourselves as temporally extended somehow. In this paper, I have argued that once we think of ourselves as temporally extended, the argument for the Extreme Claim will cease to look plausible even on the Reductionist View. Hence, it will not be any easier for us to get away with murder even if the Reductionist View is true. ${ }^{24}$

24In this paper, 1 have used some of the arguments presented in my doctoral dissertation, "The Separateness of Persons" (Princeton University, Jan. 1986). I would like to thank my advisor Tim Scanion and the readers of my dissertation, especially Michael Smith, for their comments on the dissertation. I would also like to thank Richard Savage and Ralph Kennedy for their extensive comments on an earlier version of this paper. 